\title{
CONTRASTIVE FOCUS AND EMPHASIS
}

\author{
MALTE ZIMMERMANN \\ Universität Potsdam \\ Institut für Linguistik \\ SFB 632 „Informationsstruktur“ \\ Karl-Liebknecht-Straße 24-25 \\ 14476 Golm, Germany \\ malte.zimmermann@rz.hu-berlin.de
}

\begin{abstract}
The paper puts forward a discourse-semantic account of the notoriously evasive phenomena of contrastivity and emphasis. Based on new evidence from Chadic, it is argued that occurrences of focus that are treated in terms of 'contrastive focus', 'kontrast' (VallduvíVilkuna 1998) or 'identificational focus' (É. Kiss 1998) in the literature should not be analyzed in familiar semantic terms as involving the introduction and subsequent exclusion of alternatives. Rather, an adequate analysis must take into account discourse-semantic notions like 'hearer expectation' or 'discourse expectability' of the focused content in a given discourse situation. The less expected the focus content is judged to be for the hearer, relative to the Common Ground, the more likely a speaker is to mark the focus constituent by means of special grammatical devices, thus giving rise to emphasis.
\end{abstract}

Keywords: contrastive focus, discourse expectability, emphasis, focus alternatives, grammatical marking

\section{Introduction}

According to Tomioka (2007), the notion of contrastivity is connected to diverse linguistic phenomena, such as, e.g., exhaustive answers in question-answer pairs (cf. (1a)), contrastive statements (cf. (1b)), or instances of corrective focus (cf. (1c)):

(1) (a) Q: Who did you invite?

A: Paul, I invited (but nobody else).

(b) I did not invite Peter, but Paul. 
(c) A: You invited Peter?

B: No, I invited PAUL.

While all the contrastive elements in (1) constitute instances of contrastive focus in an intuitive sense, there is considerable disagreement concerning the correct analysis of contrastive focus in intonation languages. The central questions are the following: Does contrastive focus constitute an information-structural (IS-) category of its own? That is, is contrastive focus a category distinct from the more basic notion of focus as evoking a set of contextually salient alternatives (Rooth 1985; 1992)? And if so, are there any reliable pragmatic and/or prosodic cues for its identification? Prosodic evidence from intonation languages suggests that contrastive focus is not fully independent of focus, as contrastive foci differ only gradually in intonation from information foci (see Hartmann 2008 , and references therein). In contrast, evidence from languages such as Hungarian or Finnish, in which 'contrastive' elements are realized in a particular syntactic position, suggests the opposite (É. Kiss 1998; Vallduví-Vilkuna 1998). This raises the question of what constitutes the set of characteristic semantic or pragmatic features of contrastive foci in these languages. A prominent line of research argues that contrastive foci are characterized on the basis of semantic features, such as exhaustiveness, and can therefore be diagnosed by looking at genuine semantic phenomena, such as the logical relations between sentence pairs (Szabolcsi 1981; É. Kiss 1998).

The present article argues that contrastivity should be best viewed as a discourse-semantic phenomenon with grammatical reflexes, perhaps exempting Hungarian: contrastivity in this sense means that a particular focus content or a particular speech act containing a focus is unexpected for the hearer from the speaker's perspective. One way for the speaker to direct the hearer's attention, and to get him to shift his background assumptions accordingly, is to use additional grammatical marking, e.g., intonation contour, syntactic movement, clefts, or morphological markers. This special marking seems to correlate with what is often called emphatic marking in descriptive and typological accounts of non-European languages. Contrastivity defined in this way depends on the speaker's assumptions about what the hearer considers to be likely or unlikely, introducing a certain degree of subjectivity. It follows that models for diagnosing contrastive foci must be more elaborate, containing not only 
information on the state of the linguistic and non-linguistic context as such, but also on the background assumptions of speaker and hearer.

Notice that the present contribution does not aim at giving a comprehensive overview over the vast body of literature on the notion of contrastive focus, or identification focus, as opposed to information focus (apart from the references cited above, see e.g., Halliday 1967; Chafe 1976; Couper-Kuhlen 1984; Rochemont 1986; É. Kiss 1998; Drubig-Schaffar 2001; Umbach 2001; Molnár 2002; Selkirk 2008, among many others). Nor is there any discussion of contrastive topics as such. Rather, the article sketches the author's views on the discourse-semantic origin of contrastivity in focus in a programmatic fashion. The following remarks should suffice to situate the present proposal with respect to the existing literature. Following Rooth $(1985 ; 1992)$, any kind of focus, contrastive or not, is assumed to evoke a set of alternatives against which the focus constituent is evaluated. This is opposed to proposals that assume that the evocation of alternatives is restricted to contrastive, or identification, or big FOCUs (see e.g., Vallduví-Vilkuna 1998; É. Kiss 1998; Selkirk 2008). In other words, contrastive focus is not fundamentally different from information focus, as far as its underlying semantics are concerned. What distinguishes contrastive focus from information focus, and what is new about the present proposal, is that the alternatives that play a role with contrastive focus are not just calculated relative to the semantic denotation of the focus constituent (the semantic alternatives). Instead, they are calculated relative to the focus denotation together with the speaker's suppositions as to which of these alternatives the hearer is likely to expect (the discourse-semantic alternatives). The less expected a given focus constituent $\alpha$ is in a particular context - according to the speaker - the more likely it is to get a contrastive marking.

\section{Four observations}

Let us start with four observations, mostly from West Chadic: First, Hausa and Bole (West Chadic) show a clear tendency to leave information focus on non-subjects unmarked, whereas a formal marking of non-subject foci (Hausa: movement, Bole: morphological marker) correlates with contrastive uses as illustrated in (1); cf. (2) from Bole: 
(2) Q: What did Lengi do?
A: Léngì kàpp-ák
(yé) mòrdó.
Lengi plant-perf.f.agr foc millet
- yé: 'Lengi planted MiLlet.'
+ yé: 'It was MILLET that Lengi planted!'

The formal marking of information focus and contrastive focus in these languages thus differs not only gradually, but categorically: the notion of contrast has a real impact on the grammatical system (Hartmann 2008). Bole thus differs from intonation languages, where the contrastive focus accent differs only gradually from the information focus accent. See, for instance, Bolinger (1961; 1989); Lambrecht (1994); Gibbon (1998) and Alter et al. (2001) on English and German.

Second, Gùrùntùm uniformly marks all kinds of foci by means of the focus marker $a$, typically preceding the focus constituent (HartmannZimmermann 2006). However, non-subject foci can additionally be highlighted by fronting them to sentence-initial position, using a cleft-like relative structure:

(3) Q: What did Audu catch?

A: [Á gàmshí] mài Áudù náa. foc crocodile rel Audu catch 'Audu caught A CROCODILE.'

The continued presence of the focus marker $a$ on the moved constituent suggests that contrastive foci are just special kinds of foci. This conclusion squares up with the fact that information and contrastive focus differ only gradually in intonation languages.

Third, a number of languages that allow for movement to the left periphery (e.g., Hausa, German) exhibit the phenomenon of partial focus movement. Only the most relevant part of the focus constituent moves; cf. (4) from Hausa (Hartmann-Zimmermann 2007):

(4) Q: What happened? [sentence-focus]

A: B'àràayii nèe su-kà yi mîn saatàa! robbers prt 3pl-rel.perf do to.me theft 'RoBBERs have stolen from me!' 
This suggests that movement of (part of) the focus constituent is not so much triggered by its focus status per se, but by additional semantic or discourse-pragmatic considerations.

Fourth, and most important, there is no absolute correspondence between a certain focus use (information, corrective, selective, etc.) and its being grammatically marked, or emphasized, in languages as diverse as Finnish and Hausa (Molnár-Järventausta 2003; Hartmann-Zimmermann 2007). While information foci in answers to wh-questions are typically unmarked, they can sometimes be marked as well. And while corrective foci in corrections are typically marked, they can sometimes go unmarked as well; cf. (5) from Hausa:

(5) A: You will pay 20 Naira.

B: A'a, zâ-n biyaa shâ bìyar nèe.

no fut-1sg pay fifteen prt

'No, I will pay fifteen.'

It is therefore impossible to predict the presence or absence of a contrastive marking on a focus constituent $\alpha$ just on the basis of its inherent properties, or its immediate discourse function as an answer, correction, etc. Rather, the presence or absence of a special grammatical marking on $\alpha$ depends on the specific discourse requirements at a specific point in the discourse. These are influenced by the intentions of the speaker and her assumptions about the knowledge state(s) of the hearer(s). It follows that a wider range of pragmatic factors pertaining to such knowledge states and to particular discourse goals must be considered in analyzing contrastivity. A promising formal account of relevant pragmatic factors is found in Steedman's (2006) analysis of German and English.

\section{Towards a formalization: Steedman (2006) on intonational meaning}

The main purpose of this rough sketch of Steedman's system is to demonstrate that it is possible, in principle, to develop a formally precise analysis of discourse phenomena such as the ones considered here. Steedman's (2006) main point is that pitch accents and boundary tones in German and English serve to mark more IS- and discourse-related distinctions than just the theme-rheme contrast, where theme and rheme are not 
understood as given and new, or as background and kontrast (Vallduví-Vilkuna 1998), but as context-dependent and context-independent (Bolinger 1965), respectively; cf. (6). In many cases, the rheme of an utterance corresponds to the notion of focus as used in this article. The pitch accents themselves indicate the existence of a contextually salient set of alternatives (Bolinger 1961; Rooth 1992).

Besides the theme-rheme distinction, pitch accents and boundary tones are taken to express information at a separate level of discourse structure: The kind of pitch accent chosen indicates whether an information unit is common ground $\left(\mathrm{H}^{*}\right.$ family) or not ( $\mathrm{L}^{*}$ family). Different boundary tones mark an information unit as speaker's supposition ( $\mathrm{L} \%$ family) or as hearer's supposition ( $\mathrm{H} \%$ family). Different tones thus convey information concerning the status of an information unit (theme or rheme) as being in the common ground or not, and concerning the epistemic attitudes of speaker/hearer relative to this information. ${ }^{1}$ Without going into too much detail, the following examples should give the reader a preliminary idea of the discourse-semantic effects of $\mathrm{L} \% / \mathrm{H} \%$ boundary tones and $\mathrm{L}^{*} / \mathrm{H}^{*}$ pitch accents on otherwise identical clauses:

(6) (a) You put my trousers in the Microwave! ( $\rightarrow$ You did that.)

$$
\mathrm{H}^{*} \quad \mathrm{H}^{*} \quad \mathrm{LL} \%
$$

(b) You put my trousers in the MICROWAVE? $\quad(\rightarrow$ I don't believe it! $)$

$$
\mathrm{L}^{*} \quad \mathrm{~L}^{*} \mathrm{LL} \%
$$

(c) You put my trousers in the Microwave? $\quad(\rightarrow$ You really did that? $)$

$$
\mathrm{H}^{*} \quad \mathrm{H}^{*} \quad \mathrm{LH} \%
$$

The falling declarative statement (6a) expresses the speaker's contention that the hearer's ill-treatment of her trousers should be known or acceptable to both discourse participants, and thus be part of the common ground. The all-low declarative (6b), on the other hand, expresses the speaker's unwillingness to accept the content of (6b) as part of the common ground, thus expressing an element of disbelief. The rising declarative question (6c), finally, indicates that the hearer can safely assume the proposition expressed to be entertained by both him and the speaker, as the speaker has reason to believe that this is indeed the case; cf. also Gunlogson (2003) for related ideas.

\footnotetext{
${ }^{1}$ See also Merin-Bartels (1997) for an account in the framework of decisiontheoretic semantics.
} 
What is important is that the coding of differences in the suppositions of speaker and hearer about the common ground serves an important discourse-structural function: it sets the scene for subsequent discourse moves aimed at smoothing out the assumed differences, e.g., additional explanation on the part of the speaker, or accommodation on the part of the hearer. Notice that entire utterances can be rhematic, corresponding to wide focus on the sentence. In addition, not only (asserted) propositions $(p)$, or parts of propositions, but also speech acts, such as requests (REQ) and commands (COM), can be qualified as parts (or non-parts) of the common ground (CG) relative to the speaker's or hearer's knowledge base. Depending on the chosen intonation, these will be interpreted as more or less polite by the hearer. The hierarchical organization of the various layers of information expressed by intonation is schematized in (7):

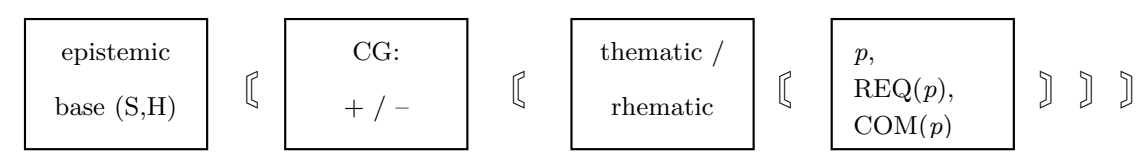

Summing up, Steedman's system provides a formal account of the meaning contribution of tones in intonation languages. These are used to express information at the two independent levels of information structure (IS) and discourse structure (DS): (i) They distinguish themes from rhemes (IS); (ii) they indicate whether the themes or rhemes are common ground (DS); (iii) they indicate the epistemic base for this evaluation (DS). What the proposed system cannot do, though, is to account for contrastivity effects as illustrated in (1), which - in intonation languages arise in connection with a more articulated pitch contour (higher target, steeper increase) or with fronting, as in scrambling or topicalization (Frey 2004). ${ }^{2}$

\footnotetext{
${ }^{2}$ Notice that, in contrast to the present proposal, Steedman (2006) does not take contrastivity to single out a specific subclass of rhemes or foci. For him (ibid., 8), contrastive focus is the same as kontrast (Vallduví-Vilkuna 1998). It is triggered by any occurrence of pitch accent that indicates the existence of a contextually salient set of alternatives. This is the very function attributed to focus in Rooth's Alternative Semantics.
} 


\section{Extending the analysis: Semantic effects of contrastive focus marking}

Taking Steedman's framework as the basis for exploring the nature of contrastive focus, let us assume that contrastive foci are used to convey information concerning the hearer's suppositions about the common ground, i.e., information at the level of discourse structure. The semantic import of contrastive focus marking is stated in (8):

(8) Contrastive Focus Hypothesis:

Contrastive marking on a focus constituent $\alpha$ expresses the speaker's assumption that the hearer will not consider the content of $\alpha$ or the speech act containing $\alpha$ likely to be(come) common ground.

According to (8), contrastive foci thus do not mark a contrast between a focus constituent $\alpha$ and other explicit or implicit alternatives to $\alpha$ that are provided by the context of the utterance. ${ }^{3}$ Rather, they express a contrast between the information conveyed by the speaker in asserting $\alpha$ and the assumed expectation state of the hearer: a speaker will use contrastive marking on a focus constituent $\alpha$ if she has reason to suspect that the hearer will be surprised by the assertion of $\alpha$, or by the speech act containing $\alpha$. Because of this, the speaker uses a non-canonical, i.e., marked, grammatical form to direct the hearer's attention, and to shift his common ground in accordance with the new information provided. This is best shown by looking at the typical and atypical patterns observed with contrastive focus marking towards the end of section 2 .

\subsection{Contrastive focus marking: Typical patterns}

Contrastive focus marking is typically absent in answers to wh-questions, cf. (9a), and typically present in correcting statements, cf. (9b):

(9) (a) Q: What did you eat in Russia?

A: We ate pelmeni.

(b) A: Surely, you ate pelmeni!

B: No, caviar, we ate! / No, we ate $\uparrow$ caviar! ( $\uparrow=$ raised pitch)

3 This discourse-oriented use of the term contrastive differs radically from the one found in Büring's (1997) analysis of contrastive topics. Büring's notion of contrastivity is semantically much weaker, simply indicating the presence of alternatives in the form of alternative subquestions that have not yet been answered. 
The absence of contrastive focus marking in (9a) is predicted by (8): the most likely speech act following on a wh-question is an answer that gives the requested information. The speaker can also assume that the hearer will not be surprised by the choice of pelmeni as her common staple in Russia, and therefore will have no problems with updating the common ground accordingly. Hence, no need for contrastive marking. In (9b), in contrast, it follows from hearer A's assertion that she does not expect to be contradicted. Also, speaker B can assume that the hearer will not consider caviar a very likely food to be had (even in Russia), and she expresses this accordingly by using a contrastive focus.

\subsection{Contrastive focus marking: Atypical patterns}

Atypical patterns are observed in connection with the presence of contrastive marking on focus constituents in answers to wh-questions, cf. (10), and with the absence of contrastive marking on corrective foci, cf. (5):

(10) Q: What did you eat in Russia?

A: Caviar we ate. / We ate $\uparrow$ caviar!

Even though an answer is expected in (10), the informational content of the focus constituent caviar is judged to be so unexpected by the speaker as to warrant a special contrastive marking on it. In the bargaining situation in (5), on the other hand, the situation is conventionalized such that the hearer can safely assume that the speaker will not be surprised by his rejecting the original price, nor by his offering a lower price. Hence, no need for contrastive marking.

There are other reasons for using contrastive focus marking in answers to $w h$-questions so as to explicitly reject a likely expectation on the side of the hearer. For example, contrastive marking can be used to reject the assumption that more than one individual will satisfy the predicate in the question; cf. (11):

(11) Q: Who (all) did you invite?

A: Peter, I invited (but nobody else).

The exhaustiveness implied by the contrastively marked answer in (11) is often taken to be a characteristic property of contrastive foci in general (É. Kiss 1998; Vallduví-Vilkuna 1998), whereas here it comes out as a 
special subcase of the more general case in (8). Notice that this is a desired outcome, for in practice it often proves difficult to demonstrate that a contrastively focused constituent has an exhaustive interpretation, the reason for this being that not all contrastive foci give rise to implicatures of exhaustiveness (see e.g., Green-Jaggar 2003 on Hausa).

Notice incidentally that many languages have lexicalized at least some of the meaning facets of contrastive focus, or its implicatures, in the form of focus-sensitive particles, such as only, expressing exhaustiveness, or even, expressing the relative unlikelihood of the asserted proposition compared to the focus alternatives ordered on a scale (Karttunen-Peters 1979). This squares up nicely with the observation that such focus particles show a tendency to occur with contrastive foci as well (Tomioka 2007): both devices have the same semantic effect on the hearer. ${ }^{4}$

Finally, it is also possible to mark only part of the focus for contrastivity, giving rise to partial movement; cf. (4). Here, only part of the focus is taken to be unexpected for the hearer, and hence in need of contrastive marking.

\section{Typological implications}

\subsection{Intonation and tone languages}

As shown, both intonation languages and Chadic tone languages can and do express contrastivity in their respective grammars. The grammatical systems of the two language groups differ in an important respect, though, which has drastic effects on the perspicuity of contrastive foci in the two groups. Intonation languages obligatorily mark the existence of a contextually salient set of alternatives, i.e., focus, by using a pitch accent. As a result, every focus, contrastive or not, carries a pitch accent, often blurring the distinction between the two. The West Chadic languages,

${ }^{4}$ The parallel between contrastive focus and the focus particle even might eventually pave the way to a further generalization of the meaning of contrastive focus. It has been argued that the presence of even does not necessarily indicate the relative unlikelihood of a proposition, but simply the presence of a scale in need of an ordering source (Kay 1990). In most cases, the ordering source for the scale will be a measure of (un)likelihood, but in certain cases it can also be assigned a special ordering source provided by the context. Extending this analysis to contrastive foci, one could argue that these, too, merely indicate the presence of a scalar ordering with the measure of (un)likelihood as its default value. 
in contrast, need not grammatically mark the existence of alternatives, i.e., focus, on non-subjects (see Hartmann-Zimmermann 2007 on the restriction to non-subjects): focused non-subjects are only marked when contrastive, which makes contrastive focus relatively easy to identify in these languages. This difference in identifiability aside, both groups of languages have comparable grammatical means, i.e., contrastive focus marking, in order to achieve the same discursive end, namely discourse maintenance by ensuring a smooth update of the common ground in situations of (assumed) differences in the suppositions of speaker and hearer. Given that the latter process can be taken to form an integral part of any inter-human conversation, the universal availability of contrastive focus marking, or emphasis, is thus not surprising.

\subsection{A note on Hungarian}

Hungarian is special in that it has a designated focus position which is filled by a focus constituent after focus movement. There are different views concerning the question of what are the triggers for focus movement, which have been argued to be syntactic (Brody 1990), or prosodic (Szendröi 2003), or semantic (Horvath 2007) in nature. The diverging opinions on the triggering factors for focus movement apart, it is relatively uncontroversial that syntactic focus marking typically gives rise to an exhaustive interpretation. Again, opinions differ as to whether this exhaustive interpretation is due to a covert exhaustivity, or exhaustive identificational (EI) operator (Szabolcsi 1981; Horvath 2007), or due to the syntactic configuration as a whole (É. Kiss 1998; 2008), and whether the effect is truth-conditional (Szabolcsi 1981), or presuppositional in nature (Kenesei 1986; Szabolcsi 1994). Still, most scholars on Hungarian would accept that the marked focus configuration in Hungarian is obligatorily accompanied by a specific semantic interpretation.

This would set Hungarian aside from all the other languages discussed so far, where the marked syntactic configuration is triggered by discourse-semantic needs, and which therefore do not come with obligatory semantic effects. However, recently is has been proposed among others by Onea (2007) that an exhaustive interpretation is not obligatory for syntactically marked foci in Hungarian either, but that the effect of exhaustivization comes about by way of pragmatic inferencing. To the extent that this claim is correct, and assuming that obligatory focus movement is not triggered by semantic needs, Hungarian would not be 
so different from languages with optional marking of contrastive focus as discussed in this article.

\section{Conclusion}

Contrastive focus marking does not so much indicate the explicit or implicit presence of contrasting alternatives in the (non-)linguistic context, although this may be a side effect, but rather a contrast between the information conveyed by the speaker in asserting $\alpha$ and the assumed expectation state of the hearer: the speaker marks the content of $\alpha$ as in her view - unlikely to be expected by the hearer, thus preparing the scene for a swifter update of the common ground. The introduction of a measure of (assumed) unlikelihood adds a moment of subjectivity to the notion of contrastivity. In diagnosing contrastivity, it will therefore not do to just look at isolated sentence pairs and the logical relations between them. Rather, it is necessary - in corpus studies - to search elaborate corpora containing information on the knowledge states of the discourse participants as well, and - in elicitation - to work with more elaborate models that specify such knowledge states.

\section{References}

Alter, Kai - Ina Mleinek - Carla Umbach - Tobias Rohe 2001. Kontrastprosodie in Sprachproduktion und -perzeption. In: Steube-Umbach (2001, 59-81).

Bolinger, Dwight 1961. Contrastive accent and contrastive stress. In: Language 37 : 83-96.

Bolinger, Dwight 1965. Forms of English. Harvard University Press, Cambridge MA.

Bolinger, Dwight 1989. Intonation and its uses. Stanford University Press, Stanford.

Brody, Michael 1990. Remarks on the order of elements in the Hungarian focus field. In: István Kenesei (ed.): Approaches to Hungarian 3 (Structures and arguments), 95-121. JATE, Szeged.

Büring, Daniel 1997. The meaning of topic and focus - The 59th Street Bridge accent. Routledge, London.

Chafe, Wallace L. 1976. Givenness, contrastiveness, definiteness, subjects, topics and point of view. In: Charles N. Li (ed.): Subject and topic, 27-55. Academic Press, New York.

Couper-Kuhlen, Elisabeth 1984. A new look at contrastive intonation. In: Richard J. Watts - Urs Weidmann (eds): Modes of interpretation. Essays presented to Ernst Leisi on the occasion of his 65th birthday, 137-58. Gunter Narr, Tübingen. 
Drubig, Hans Bernhard - Wolfram Schaffar 2001. Focus constructions. In: Martin Haspelmath - Ekkehard König - Wulf Österreicher - Wolfgang Raible (eds): Language typology and language universals. An international handbook, 1079-104. Mouton de Gruyter, Berlin \& New York.

É. Kiss, Katalin 1998. Identificational focus versus information focus. In: Language $74: 245-73$.

É. Kiss, Katalin 2008. Topic and focus: Two structural positions associated with logical functions in the left periphery of the Hungarian sentence. In: Acta Linguistica Hungarica $55: 287-96$.

Frey, Werner 2004. The grammar-pragmatics interface and the German prefield. In: Sprache und Pragmatik 52:1-39.

Gibbon, Dafydd 1998. German intonation. In: Daniel Hirst-Albert di Cristo (eds): Intonation systems. A survey of twenty languages, 78-95. Cambridge University Press, Cambridge.

Green, Melanie-Philipp M. Jaggar 2003. Ex-situ and in-situ focus in Hausa: Syntax, semantics and discourse. In: Jacqueline Lecarme (ed.): Research in Afroasiatic grammar 2 (Current Issues in Linguistic Theory), 187-213. John Benjamins, Amsterdam \& Philadelphia.

Gunlogson, Christine 2003. True to form: Rising and falling declaratives as questions in English. Routledge, New York.

Halliday, Michael Alexander Kirkwood 1967. Notes on transitivity and theme in English, Part II. In: Journal of Linguistics $3: 199-244$.

Hartmann, Katharina 2008. Focus and emphasis in tone and intonation languages. In: Anita Steube (ed.): The discourse-potential of underspecified structures: Event structures and information structure, 389-412. Mouton de Gruyter, Berlin \& New York.

Hartmann, Katharina - Malte Zimmermann 2006. Morphological focus marking in Gùrùntùm (West Chadic). Manuscript. Humboldt University, Berlin.

Hartmann, Katharina - Malte Zimmermann 2007. In place-out of place: Focus in Hausa. In: Kerstin Schwabe-Susanne Winkler (eds): On information structure, meaning and form: Generalizatons across languages, 365-403. John Benjamins, Amsterdam \& Philadelphia.

Horvath, Julia 2007. "Discourse features", syntactic displacement and the status of contrast. Manuscript. Tel Aviv University.

Karttunen, Lauri - Stanley Peters 1979. Conventional implicature. In: Choon-Kyu Oh-David A. Dinneen (eds): Syntax and semantics 11: Presupposition, 1-56. Academic Press, New York.

Kay, Paul 1990. Even. In: Linguistics and Philosophy 13:59-111.

Kenesei, István 1986. On the logic of Hungarian word order. In: Werner AbrahamSjaak de Meij (eds): Topic, focus, and configurationality, 143-59. John Benjamins, Amsterdam.

Lambrecht, Knud 1994. Information structure and sentence form. A theory of topic, focus, and the mental representations of discourse referents. Cambridge University Press, Cambridge. 
Merin, Arthur-Christine Bartels 1997. Decision-theoretic semantics for intonation. In: Arbeitspapiere des SFB 340 88:1-17.

Molnár, Valéria 2002. Contrast from a contrastive perspective. In: H. HallelgardStig Johansson-Bergljot Behrens-Cathrine Fabricius-Hansen (eds): Information structure in a cross-linguistic perspective, 147-61. Rodopi, Amsterdam \& New York.

Molnár, Valéria-Maria Järventausta 2003. Discourse configurationality in Finnish and Hungarian. In: Jorunn Hetland-Valéria Molnár (eds): Structures of focus and grammatical relations, 111-48. Niemeyer, Tübingen.

Onea, Edgar 2007. Exhaustivity, focus and incorporation in Hungarian. In: Maria Aloni-Paul Dekker-Floris Roelofsen (eds): Proceedings of the 16th Amsterdam Colloquium, 169-74. ILLC, Amsterdam.

Rochemont, Michael 1986. Focus in generative grammar. John Benjamins, Amsterdam.

Rooth, Mats 1985. Association with focus. Doctoral dissertation, University of Massachusetts, Amherst.

Rooth, Mats 1992. A theory of focus interpretation. In: Natural Language Semantics $1: 75-116$.

Selkirk, Elisabeth O. 2008. Contrastive focus, givenness and the unmarked status of "discourse-new". In: Acta Linguistica Hungarica 55 : 331-46.

Steedman, Marc 2006. Evidence for a semantics and pragmatics of intonation. Paper presented at the 2nd Conference on Linguistic Evidence, University of Tübingen, February 2006.

Steube, Anita - Carla Umbach (eds) 2001. Linguistische Arbeitsberichte 77. Institut für Linguistik, Leipzig.

Szabolcsi, Anna 1981. The semantics of topic-focus articulation. In: Jeroen Groenendijk - Theo Janssen - Martin Stokhof (eds): Formal methods in the study of language, 513-41. Matematisch Centrum, Amsterdam.

Szabolcsi, Anna 1994. All quantifiers are not equal: The case of focus. In: Acta Linguistica Hungarica $42: 171-87$.

Szendrői, Kriszta 2003. A stress-based approach to the syntax of Hungarian focus. In: The Linguistic Review $20: 37-78$.

Tomioka, Satoshi 2007. Contrastive topics operate on speech acts. Manuscript. University of Delaware.

Umbach, Carla 2001. Restriktion der Alternativen. In: Steube-Umbach (2001, 16598).

Vallduví, Enric- Maria Vilkuna 1998. On rheme and kontrast. In: Peter CulicoverLouise McNally (eds): The limits of syntax, 79-106. Academic Press, New York. 